 \\ Особенности реализации концепта ВОЗРАСТ ЖЕНЩИНЫ и его искажения в новостном дискурсе
}

\author{
Юань Линь, Сяо Дунся
}

\begin{abstract}
Аннотация. Цель исследования - выявление искажений концепта ВОЗРАСТ ЖЕНЩИНЫ в новостном дискурсе российских электронных СМИ. Научная новизна исследования состоит в том, что в нем впервые поднимаются как вопрос о реализации в новостном дискурсе концепта ВОЗРАСТ ЖЕНЩИНЫ, так и проблема искажений данного концепта. В результате выявлены и описаны такие искажения, как преуменьшение возраста женщины и игнорирование возрастных характеристик женщины. Данные искажения воспроизводят стереотипы, исторически сложившиеся в восприятии женского возраста в русской лингвокультуре и отражающие зависимое положение женщины. Анализ концепта ВОЗРАСТ ЖЕНЩИНЫ позволяет реконструировать стоящий за ним фрагмент русской языковой картины мира.
\end{abstract}

\section{Implementation Features of the WOMAN'S AGE Concept and Its Distortions in News Discourse}

\author{
Yuan Lin, Xiao Dongxia
}

\begin{abstract}
The aim of the study is to identify the distortions of the WOMAN'S AGE concept in the news discourse of Russian online media. The scientific originality of the study lies in the fact that it for the first time raises both the question of the implementation of the WOMAN'S AGE concept in news discourse, and the problem of this concept distortions. As a result, such distortions as underestimation of woman's age and ignorance of woman's age characteristics were identified and described. These distortions reproduce stereotypes historically formed in the perception of female age in Russian linguistic culture and reflecting the dependent position of women. The analysis of the WOMAN'S AGE concept allows reconstructing the fragment of the Russian linguistic worldview behind it.
\end{abstract}

\section{Введение}

Средства массовой информации (СМИ) стали сегодня важнейшей сферой использования современного русского языка, в которой наиболее отчетливо проявляются все тенденции развития как языка в целом, так и его концептосферы в частности. Концептосфера включает многообразные мыслительные конструкты человеческого сознания, или концепты, определяемые как «основные ячейки культуры в ментальном мире человека» (Степанов, 2004, с. 43), при этом «ментальность народа актуализируется в наиболее важных культурных концептах языка» (Крылова, 2014, с. 52). Концепт понимается нами как конструкт лингвокультуры, который «не воссоздается, а “реконструируется” через свое языковое выражение и внеязыковое сознание» (Телия, 1996, с. 57). Новостной дискурс представляет собой одну из составляющих медиа-дискурса, и его характерологическими чертами являются краткость содержания, выделение главного события, указание на фон или контекст, присутствие вербальных реакций и комментариев (Школьникова, 2018, с. 783), а также «манипулятивный потенциал» (Карабулатова, 2021, с. 41), то есть потенциальная возможность оказания влияния на сознание адресата. В новостном дискурсе получают преломление различные концепты русского языка, в первую очередь наиболее актуальные, связанные с сущностью русской культуры, с менталитетом и миропониманием русского человека, с современной общественной и политической ситуацией: «любовь» (Иванова, 2019), «патриотизм» (Лебедев, 2016), «терроризм» (Кухарева, 2018) и др. Концепт ВОЗРАСТ ЖЕНЩИНЫ как составляющая концептосферы русского языка относится к числу наименее изученных, причем не только применительно к новостному дискурсу, в то время как данный концепт очень важен для понимания особенностей русской ментальности.

Актуальность данного исследования определяется важностью анализа новостного медиадискурса с точки зрения его лингвокультурологических функций, выражения в нем составляющих картины мира носителя языка и концептосферы языка. Каждый значимый для русской языковой картины мира концепт получает 
в медиадискурсе свое отражение, анализ которого демонстрирует особенности концептуального восприятия того или иного явления на данном этапе развития общества, новообразования в нем и степень его соответствия традиционным представлениям.

В соответствии с поставленной целью в ходе исследования решались следующие задачи: во-первых, выявить в современном новостном дискурсе российских электронных СМИ реализации концепта ВОЗРАСТ ЖЕНЩИНЫ; во-вторых, выявить искажения данного концепта в новостном дискурсе; в-третьих, оценить искажения с точки зрения их культурологических оснований, отражения с их помощью ментальности носителя языка. Исследование проводилось на материале новостных публикаций популярного электронного издания «Газета.ru» (https://www.gazeta.ru). Именно интернет-СМИ с их возможностью быстрого реагирования на события становятся сегодня основными способами реализации новостного дискурса.

Для достижения поставленной цели и выполнения задач использовались следующие методы исследования: общенаучные методы наблюдения, анализа и синтеза при работе с научной литературой, методы сопоставления и систематизации, а также метод лингвокогнитивного анализа при анализе текстовых реализаций концепта ВОЗРАСТ ЖЕНЩИНЫ, метод сплошной выборки при отборе языкового материала.

Теоретической базой стали труды в области концептологии (Иванова, 2019; Крылова, 2014; Кухарева, 2018; Лебедев, 2016; Степанов, 2004) в целом и работы, посвященные изучению концепта ВОЗРАСТ в частности (Есиркеева, 2017; Кондратьева, Любина, 2017; Крючкова, 2003; Любина, 2006). Общий методологический принцип исследования заключается в комплексном рассмотрении языковых способов выражения концепта и в выявлении стоящих за ним фрагментов языковой картины мира.

Практическая значимость исследования заключается в возможности использования его результатов в процессе преподавания вузовских курсов по журналистике, лингвокультурологии, а также курсов и спецкурсов по новостному дискурсу и его концептуальным основам, по гендерной лингвистике.

\section{Основная часть}

Разработке в лингвокультурологии подвергается прежде всего концепт ВОЗРАСТ и его составляющие концепты ДЕТСТВО, ЮНОСТЬ, МОЛОДОСТЬ, ЗРЕЛОСТЬ, СТАРОСТЬ - причем для названных сегментов «соседние зоны пересекаются и накладываются друг на друга» (Крючкова, 2003, с. 4). Деление концепта ВОЗРАСТ на компоненты, которые отражают этапность жизни человека, делает данный концепт сегментным (Есиркеева, 2017, с. 41). Исследователями признается, что концептуальная информация о возрасте «может использоваться в речи (например, в публицистическом или политическом дискурсе) как один из очень действенных способов формирования оценки высказывания» (Любина, 2006, с. 3). Для русского менталитета характерны «резкое противопоставление детства и старости или молодости и старости», негативная оценка старости, стереотипность (Кондратьева, Любина, 2017, с. 154-155) и другие особенности восприятия данного концепта.

К сожалению, концепт ВОЗРАСТ ЖЕНЩИНЫ, существование которого наряду с концептом ВОЗРАСТ МУЖЧИНЫ определяется антропологическим фактором (отражением в языке человека его физиологических, социальных и других особенностей), является в настоящий момент недостаточно разработанным предметом лингвокультурологического и лингвокогнитивного исследования. Отражение гендерного фактора в функционировании концепта ВОЗРАСТ не изучается, в то время как трансформации восприятия возраста женщины в современной России «в условиях увеличивающейся продолжительности жизни, сокращающихся ресурсов на обеспечение старости и возрастающей неопределенности будущего» отмечаются социологами (Григорьева, Сизова, 2018, с. 109). В новостном дискурсе СМИ концепт ВОЗРАСТ ЖЕНЩИНЫ получает яркое и концентрированное выражение, что и привлекает к нему наше внимание.

Возраст женщины, по стереотипным суждениям представителей русской лингвокультуры, является понятием табуированным. К примеру, у женщин не принято спрашивать о возрасте, а сам возраст часто приуменьшают, что считается вполне приемлемым в восприятии общества. Этот фактор не может не отражаться в новостном дискурсе. Стереотипы являются важными составляющими концепта, «результатом отражения в сознании личности “типового” фрагмента реального мира, неким инвариантом определенного участка картины мира» (Красных, 2002, с. 177-178).

Одним из ярких проявлений искажения информации о возрасте женщины является функционирование в новостном дискурсе такого языкового репрезентанта концепта ВОЗРАСТ ЖЕНЩИНЫ, как слово девушка. В словаре данная лексема определяется как 'лицо женского пола, достигшее половой зрелости, но не состоящее в браке' (Ефремова, 2000). Однако в текстах новостей с ее помощью могут назвать и замужнюю, и ставшую матерью молодую женщину. Например: «17 сентября девушка впервые стала мамой - она родила дочь, которую назвали Миланой» (Газета.ru, 22.09.2021). С помощью данной лексемы в русском языке называют и гражданскую жену, или сожительницу, что также искажает исходное значение данного возрастного наименования. Например: «Сегодня Франчетти содержится в тюрьме “Панкрац" и, по словам его девушки Светланы, находится в тяжелом состоянии и постоянно нуждается в медицинском контроле» (Газета.ru, 23.09.2021). Как видим, искажения концепта ВОЗРАСТ ЖЕНЩИНЫ касаются в первую очередь уменьшения возраста.

Наиболее частотной лексемой, указывающей на возраст женщины, является в новостном дискурсе слово женщина, имеющее в русском языке семантику 'лицо женского пола, состоящее или состоявшее в браке' (Ефремова, 2000), то есть указывающее на средний возраст объекта. Например, из одной из публикаций адресат узнает: «Женщина оскорбляла экипаж и провоцировала с ними драку», а далее в описании новости читает: «Дебоширкой оказалась 30-летняя жительница Тверской области» (Газета.ru, 24.09.2021). Такое использование слова 
женщина наиболее типично, однако с помощью данной лексемы в СМИ называют женщин различного возраста, причем не только среднего, зрелого, как в примере выше, но и пожилого, что вновь указывает на такое искажение концепта ВОЗРАСТ ЖЕНЩИНЫ, как уменьшение возраста, а также на игнорирование возрастных особенностей женщины. Например: «На юге Москвы женщину насмерть сбил автомобиль каршеринга. Установлено, что 60-летняя пенсионерка переходила дорогу в неположенном для перехода месте» (Газета.ru, 24.09.2021).

Важным компонентом концепта ВОЗРАСТ ЖЕНЩИНЫ мы считаем также само обсуждение проблемы женского возраста, причем именно здесь обнаруживаются причины искажений, направленных на уменьшение возраста. Например: «У женщин возраст все отнимает. Каждый год - минус что-то важное, что-то легкое, что-то живое» (Газета.ru, 20.04.2021). С учетом данной точки зрения, отражающей широко распространенный в обществе стереотип, отмечаемые нами искажения вполне обоснованы.

Помимо лексем женщина и девушка, к основным словам, вербализующим в СМИ концепт ВОЗРАСТ ЖЕНЩИНЫ, относятся девочка, школьница и др. Это наименования женщин юного возраста, что делает их приемлемыми с учетом стереотипов и не ограничивает их употребление. В использовании лексемы девочка также наблюдаются искажения, когда с ее помощью именуют женщин более старшего возраста, к примеру, продавщиц: «Мужчиныклиенты легче отказывают мальчикам-продавцам, чем девочкам-продавцам» (Газета.ru, 22.09.2021). Происходит уже отмеченное выше преуменьшение возраста, причем в данном примере - и мужского, и женского.

Можно выделить ряд лексических единиц с семантикой возраста женщины, которые используются в новостном дискурсе крайне редко, притом имеют специфическую окраску и семантику. Это слова дева, баба, барышня, молодуха, дама, старуха, старушка, бабулька и др. С их помощью не только называют женщин того или иного возраста, но и транслируют какие-то убеждения, например, мысль о гендерном неравенстве: «Ходу мне не давали. Потому что баба, оказывается» (Газета.ru, 20.04.2021). Кроме того, посредством подобных наименований авторами публикаций передаются иронические смыслы: «Представим себе пылкого юношу (или пылкую деву), который (которая) хочет посвятить себя обществу» (Газета.ru, 28.01.2021); негативное отношение к женщинам, совершающим какие-то предосудительные в глазах общества поступки: $B$ итоге барышни будут обращаться в подпольные клиники и в конце концов пытаться устроить аборт самостоятельно» (Газета.ru, 29.05.2020). Отметим также, что данные лексемы не соответствуют формату СМИ, и их роль как репрезентантов концепта ВОЗРАСТ ЖЕНЩИНЫ снижается. Данные единицы с семантикой возраста наблюдаются скорее не в новостном дискурсе, а в более крупном формате медиа-дискурса.

Лексемы, называющие пожилых женщин (старуха, старушка, бабулька, бабка и др.), встречаются в новостном дискурсе редко (во-первых, поскольку называют пожилой возраст, во-вторых, в силу стилистического несоответствия СМИ) и всегда каким-то образом обусловлены. Они обладают сниженной стилистической окраской, используются с коннотативными, ироническими, экспрессивными, характерологическими целями. Например, подобная лексема может подчеркивать, что какое-то мнение является несовременным, устаревшим: «Одна бабулька когда-то сказала по телевизору, что гласность - это и есть свобода слова» (Газета.ru, 12.08.2021).

К стилистически окрашенным лексемам относится также слово молодуха, используемое в СМИ, как правило, с негативной оценкой: «Цекало бросил жену и детей ради молодухи» (Газета.ru, 11.03.2019); «Можно больше не бояться беспринцинных молодух в мини...» (Газета.ru, 12.08.2015). Искажение в данном случае семантическое: для современного носителя языка молодуха - это просто молодая женщина (иногда с оттенком 'слишком молодая для чего-то'), в то время как в литературном языке слово имеет значение 'невестка, сноха' (Ефремова, 2000), в культуре - женщина в течение первого года после свадьбы.

Лексема дама употребляется в новостном дискурсе как синоним слова женщина и, как правило, используется в ироническом контексте, нередко с насмешкой или со скрытым осуждением совершаемых женщиной действий. Например: «В первый раз его дамы оттащили, приехало такси и они должны были уехать» (Газета.ru, 14.09.2021); «Но дама все-таки сообщила о произошедшем в органы внутренних дел» (Газета.ru, 12.09.2021). Искажения концепта ВОЗРАСТ ЖЕНЩИНЫ проявляются при этом посредством игнорирования реального возраста женщины, обозначаемой словом дама.

В языковом выражении концепта ВОЗРАСТ ЖЕНЩИНЫ отмечается также такое нововведение, как использование феминитивов - «альтернативных названий лиц женского пола по профессии и роду занятий именам существительным со значением мужского пола» (Диденко, Садченко, 2018, с. 205). Например: «Битва талантливых юниорок: Петросян лидирует, Самоделкина - вне топ-3» (Газета.ru, 23.09.2021). Феминитивы призваны подчеркнуть принадлежность представителя определенной профессии или социальной группы к женскому полу, они отталкиваются от наименований мужского рода: юниор - юниорка. В современном русском языке их можно назвать единицами, дополняющими языковую реализацию концепта ВОЗРАСТ ЖЕНЩИНЫ.

\section{Заключение}

Завершая исследование, мы приходим к следующим выводам.

1. Концепт ВОЗРАСТ ЖЕНЩИНЫ находит в современных СМИ и в новостном дискурсе регулярное выражение как посредством часто используемых лексических единиц (женщина, девушка, девочка), так и с помощью более редко употребляемых (баба, барышня, дева, а также феминитивов).

2. Отмечаются искажения концепта ВОЗРАСТ ЖЕНЩИНЫ в новостном дискурсе, состоящие либо в уменьшении возраста, либо в игнорировании возрастных отличий между женщинами.

3. Данные искажения коррелируют со стереотипными представлениями о том, что возраст портит женщину, что молодая женщина более привлекательна и перспективна, чем зрелая и пожилая. Исследование 
реализации концепта ВОЗРАСТ ЖЕНЩИНЫ в новостном дискурсе позволяет заметить, что данные стереотипы являются константными составляющими русского менталитета и представляют собой фрагмент русской языковой картины мира.

Перспективы дальнейших научных изысканий могут состоять в сопоставительном исследовании универсального концепта ВОЗРАСТ ЖЕНЩИНЫ на материале различных языков, в выделении общих и специфических черт понимания данного концепта в разных лингвокультурах, а также в анализе трансформаций и искажений, которым подвергается концепт ВОЗРАСТ ЖЕНЩИНЫ в художественной литературе, массовой культуре, СМИ, устной речи и т.п.

\section{Источники | References}

1. Григорьева И. А., Сизова И. Л. Траектории старения женщин в современной России // Мир России. Социология. Этнология. 2018. Т. 27. № 2.

2. Диденко А. С., Садченко В. Т. Феминитивы в современном русском языке // Современные научные исследования и разработки. 2018. Т. 1. № 12 (29).

3. Есиркеева Д. А. Фразеологические репрезентанты сегментного концепта «возраст» в русском языке // Наука России: цели и задачи: сб. науч. тр. по мат. II Междунар. науч. конф. Самара: Л.-Журнал, 2017.

4. Ефремова Т. Ф. Новый толково-словообразовательный словарь русского языка. 2000. URL: http://www.classes.ru/ all-russian/russian-dictionary-Efremova.htm

5. Иванова И. А. Особенности репрезентации концепта «любовь» в текстах СМИ // Актуальные теории, концепции, прикладной характер современных научных исследований: сб. науч. ст. по ит. Междунар. науч.практ. конф. СПб.: Изд-во Санкт-Петербургск. гос. эконом. ун-та, 2019.

6. Карабулатова И. С. Образ Китая в лингвоинформационной модели современного медиадискурса (на материале русских и китайских СМИ) // Вестник Северного (Арктического) федерального университета имени М. Ю. Ломоносова. Серия «Гуманитарные и социальные науки». 2021. Т. 1. № 4.

7. Кондратьева Т. С., Любина И. М. Национально-культурное наполнение концепта «возраст», характерное для русского менталитета // Когнитивно-дискурсивное пространство в современном гуманитарном знании: сб. науч. тр. / под ред. И. П. Хутыз. Краснодар: Изд-во Кубанск. гос. ун-та, 2017.

8. Красных В. В. Этнопсихолингвистика и лингвокультурология: курс лекций. М.: Гнозис, 2002.

9. Крылова М. Н. Семантика современного русского сравнения. Лингвокультурологический анализ: монография. Саратов: Вузовское образование, 2014.

10. Крючкова Н. В. Концепты возраста (на материале русского и французского языков): автореф. дисс. ... к. филол. н. Саратов, 2003.

11. Кухарева М. Ю. Вербальная репрезентация концепта «терроризм» в новостном дискурсе СМИ ФРГ (на материале интернет-порталов) // Вестник Самарского университета. История, педагогика, филология. 2018. T. 24. № 4.

12. Лебедев А. А. Семантика концепта «патриотизм» в новостном дискурсе телеканала «Звезда»// Вестник Волжского университета им. В. Н. Татищева. 2016. Т. 1. № 3.

13. Любина И. М. Аксиология концепта «возраст» в русской, британской и американской лингвокультурах: автореф. дисс. ... к. филол. н. Краснодар, 2006.

14. Степанов Ю. С. Константы: словарь русской культуры. М.: Академический Проект, 2004.

15. Телия В. Н. Русская фразеология. Семантический, прагматический и лингвокультурный аспекты. М.: Языки русской культуры, 1996.

16. Школьникова М. Л. Особенности новостного дискурса как одной из составляющих медиа-дискурса // Современные научные исследования и разработки. 2018. Т. 2. № 11 (28).

\section{Информация об авторах | Author information}

\section{RU Юань Линь}

Сяо Дунся ${ }^{2}$

1,2 Российский университет дружбы народов, г. Москва

EN Yuan Lin 1

Xiao Dongxia ${ }^{2}$

${ }_{1,2}$ Peoples' Friendship University of Russia, Moscow

11130132851@qq.com, 2xiaoxiaxia@yandex.com

\section{Информация о статье | About this article}

Дата поступления рукописи (received): 06.10.2021; опубликовано (published): 30.11.2021.

Ключевые слова (keywords): русский язык; СМИ; новостной дискурс; концепт ВОЗРАСТ ЖЕНЩИНЫ; искажение; Russian language; MASS MEDIA; news discourse; WOMAN’S AGE concept; distortion. 